A N N A L E S Annales de Bretagne et des Pays de l'Ouest

BRETAGNE PAYS DE LOUEST

Anjou. Maine. Poitou-Charente. Touraine

125-1 | 2018

Tolérance et intolérance des religions en Europe, $\mathrm{XVI}$ -

XVIII siècle

\title{
Fondamentalisme et intolérance : le regard d'historiens des guerres de Religion sur le djihadisme contemporain
}

Fundamentalism and intolerance: the analysis of contemporary Jihadism by

historians of the Wars of Religion

\section{François Brizay}

\section{Q OpenEdition}

Journals

Édition électronique

URL : http://journals.openedition.org/abpo/3783

DOI : $10.4000 /$ abpo.3783

ISBN : 978-2-7535-7536-3

ISSN : 2108-6443

Éditeur

Presses universitaires de Rennes

Édition imprimée

Date de publication : 30 mars 2018

Pagination : 137-150

ISBN : 978-2-7535-7491-5

ISSN : 0399-0826

\section{Référence électronique}

François Brizay, «Fondamentalisme et intolérance : le regard d'historiens des guerres de Religion sur le djihadisme contemporain ", Annales de Bretagne et des Pays de l'Ouest [En ligne], 125-1 | 2018, mis en ligne le 30 mars 2020, consulté le 06 janvier 2021. URL : http://journals.openedition.org/abpo/3783 ; DOI : https://doi.org/10.4000/abpo.3783 


\title{
Fondamentalisme et intolérance : le regard d'historiens des guerres de Religion sur le djihadisme contemporain
}

\author{
François BRIZAY \\ Professeur d'histoire moderne, université de Poitiers, CRIHAM-EA 4270
}

Les hommes politiques et les journalistes affirment souvent que les commanditaires et les exécutants des attentats commis au nom de l'État islamique, d'al-Qaïda ou de l'une de ses branches sont des "barbares", des " monstres", des "fous ", des " nihilistes ". Les sociétés visées, en état de sidération au lendemain d'un acte terroriste, ne voient dans ce dernier qu'irrationalisme et fanatisme, et se persuadent du caractère exceptionnel, unique de cette violence.

En essayant de prendre du recul par rapport aux événements, les sciences humaines tentent d'expliquer que cette violence n'est pas une fatalité et obéit à des motivations rationnelles. Trois historiens, spécialistes de l'histoire culturelle du $\mathrm{XVI}^{\mathrm{e}}$ siècle et des guerres de Religion en France, ont rédigé deux ouvrages concis à propos de l'intolérance et de la violence islamistes qu'ils analysent à la lumière de ce que nous apprend l'étude des conflits religieux que l'Europe a connus aux XVI ${ }^{\mathrm{e}}$ et $\mathrm{XVII}^{\mathrm{e}}$ siècles. Ces deux ouvrages, Les religions meurtrières, d'Élie Barnavi ${ }^{1}$ et $A u$ péril des guerres de Religion. Réflexions de deux historiens sur notre temps, de Denis Crouzet et Jean-Marie Le Gall ${ }^{2}$, ont été écrits dans l'urgence, par des auteurs de générations différentes.

Elie Barnavi a publié son livre au terme des quatre années où ont été commis des attentats aux États-Unis le 11 septembre 2001, à Madrid le 11 mars 2004, à Londres le 7 juillet 2005. Denis Crouzet et Jean-Marie Le Gall ont écrit le leur au lendemain des attentats perpétrés à Paris en janvier 2015, mais avant ceux du 13 novembre 2015.

1. Paris, Flammarion, 2006, 170 p.

2. Paris, PUF, mai 2015, $90 \mathrm{p}$. 
Élie Barnavi est un universitaire israélien doté d'une expérience militaire et diplomatique. Il a en effet connu l'expérience du combat lorsqu'il faisait son service militaire dans une unité de parachutistes pendant la guerre des Six Jours, et il fut ambassadeur d'Israël en France de 2000 à 2002. Après avoir étudié l'histoire dans les universités de Jérusalem et de Tel Aviv, il a préparé à la Sorbonne une thèse qui fut éditée sous le titre Le parti de Dieu : étude sociale et politique des chefs de la ligue parisienne 1585-1594². Il a également publié, avec Robert Descimon, La Sainte-Ligue, le juge et la potence : L'assassinat du président Brisson (15 novembre 1591) ${ }^{4}$, et il a rédigé des essais sur les guerres : Tuez-les tous! : La guerre de religion à travers l'histoire VII ${ }^{e}$ XXI siècle $^{5}$, Dix thèses sur la guerre ${ }^{6}$.

Denis Crouzet et Jean-Marie Le Gall sont professeurs d'histoire moderne à la Sorbonne. Leurs travaux sont consacrés notamment à la violence. D. Crouzet a ainsi publié Les Guerriers de Dieu : La Violence au temps des troubles de religion (v. 1525-v. 1610) ${ }^{7}$, La Nuit de la Saint-Barthélemy: Un rêve perdu de la Renaissance ${ }^{8}$ et Dieu en ses royaumes : Une histoire des guerres de Religion ${ }^{9}$. J.-M. Le Gall évoque dans L'honneur perdu de François I $^{\text {r }}$ : Pavie, $1525^{10}$ la violence des guerres d'Italie.

Élie Barnavi a conçu son livre comme un "pamphlet politique ", sans notes de bas de page, adressé à un Européen à qui il présente neuf thèses pour lui faire partager un peu de son expérience des " fous de Dieu " et l'armer moralement pour affronter ce qu'il nomme " la guerre pour la sauvegarde de vos valeurs, de vos libertés, de votre mode de vie " (p. 18). Il s'intéresse à la violence meurtrière à laquelle se livrent des hommes qui se réclament de Dieu, car il estime que les Européens, et particulièrement les Français, sont d'autant plus surpris par cette violence que " la religion est l'angle mort de [n]otre regard d'Occidental " (p. 10). L'ouvrage de D. Crouzet et de J.-M. Le Gall est un essai qui développe sept thèmes afin d'aider le lecteur à « identifier les problèmes, lever les ambiguïtés et éviter les généralités ou les amalgames " (p. 2).

Les trois historiens expliquent comment l'intolérance religieuse des chrétiens du XVI ${ }^{\mathrm{e}}$ siècle et des islamistes du XXI ${ }^{\mathrm{e}}$ siècle prend sa source dans le fondamentalisme et l'eschatologie. Ils décrivent ensuite les caractéristiques de la violence commise au nom de la religion. En tant que citoyens engagés, ils ne s'en tiennent cependant pas à une comparaison entre deux époques, mais envisagent les conditions d'un apaisement des passions religieuses dans l'Europe du $\mathrm{XxI}^{\mathrm{e}}$ siècle en insistant sur la lutte contre le

\footnotetext{
3. Paris, Publications de la Sorbonne, 1980, 388 p.

4. Paris, Hachette, 1985, 331 p.

5. Avec Anthony Rowley, Paris, Perrin, 2006, 149 p.

6. Paris, Flammarion, coll. "Café Voltaire ", 2014, 141 p.

7. Seyssel, Champ Vallon, 1990, $793+737$ p.

8. Paris, Fayard, 1994, 656 p.

9. Seyssel, Champ-Vallon, 2008, 537 p.

10. Paris, Payot, 2015, 491 p.
} 
fondamentalisme révolutionnaire musulman et sur l'importance d'un enseignement tourné vers une réflexion sur la tolérance.

\section{Le fondamentalisme et l'eschatologie}

Les auteurs voient dans les terroristes islamistes des hommes qui leur rappellent les "fous de Dieu " du $\mathrm{XVI}^{\mathrm{e}}$ siècle : comme eux, ils sont mus par une lecture fondamentaliste des textes sacrés, une eschatologie apocalyptique et une haine pour tous ceux qui ne partagent ni leur foi, ni leurs valeurs.

\section{Définir le fondamentalisme}

Élie Barnavi, qui trouve les sources de la violence religieuse dans le fondamentalisme, distingue le fondamentaliste de l'intégriste : le fondamentaliste cherche le retour aux éléments de base de sa foi, tandis que l'intégriste entend figer toute évolution des croyances et des pratiques dans un système qu'il croit définitif et immuable, dans une tradition que l'usage et l'autorité des anciens auraient sacralisée une fois pour toutes. Il analyse donc le fondamentalisme comme une lecture particulière de la religion : pour dégager la vérité des textes sacrés, qui sont toujours obscurs, il faut les interpréter; or les interprétations sont sacralisées à leur tour et forment un corpus interprétable à l'infini qui invite à retourner aux sources. Aux XVI ${ }^{\mathrm{e}}$ et XVII ${ }^{\mathrm{e}}$ siècles, en Europe, les humanistes et les réformés effectuèrent ce travail de retour aux sources et traduisirent la Bible dans les langues vernaculaires, car ils estimaient qu'il fallait lire la parole de Dieu, et non pas ses exégètes. Pour préciser sa pensée, É. Barnavi donne l'exemple suivant : Érasme était fondamentaliste, mais pas intégriste, alors que les membres de la Fraternité SaintPie X, créée par $\mathrm{M}^{\mathrm{gr}}$ Lefebvre, sont intégristes, mais pas fondamentalistes.

Élie Barnavi constate que le fondamentalisme ne conduit pas nécessairement à la violence et admet l'existence de deux fondamentalismes pacifiques. Le premier prône un effort individuel, d'ordre intellectuel et spirituel, pour retrouver les origines de sa religion, mais il ne recourt pas à la violence pour renverser l'ordre impie existant et imposer à la société l'idéal défini par une lecture fondamentaliste des textes sacrés. Érasme incarne ce courant. Le second fondamentalisme pacifique conteste le monde dans lequel il vit en s'organisant en Églises ou en courants théologiques. Ses partisans vivent en marge de la majorité de la société, se marient entre eux, mais ne menacent pas ceux qui ne partagent pas leur foi. Les groupuscules millénaristes du protestantisme, comme les anabaptistes, les mennonites ou les amish, représentent ce courant (p. 41-42).

Ces exemples montrent que, pour É. Barnavi, la tentation fondamentaliste n'est pas propre à l'islam : tous les monothéismes l'ont connue. Aujourd'hui, l'un des plus dangereux, à ses yeux, est le wahhabisme. Ce mouvement de l'islam sunnite, fondé au XvIII siècle par le prédicateur 
Muhammad ibn Abd al-Wahhab, s'efforce de restaurer ce qu'il croit être un islam originel, fidèle à la lettre du Coran. Il développe ainsi une conception puritaine et rigoriste de l'islam (p. 40-41).

Pour expliquer le passage du fondamentalisme à l'intolérance, Élie Barnavi utilise le concept de " fondamentalisme révolutionnaire ». Il désigne ainsi le mouvement qui recourt à la violence au nom de la religion et propose ce qu'il nomme " une lecture totalitaire de la religion ". Les monothéismes sont des religions d'après lesquelles il y aura une fin, un Jugement dernier. Cette conception de l'histoire est génératrice d'angoisse personnelle et collective. Que peut faire le croyant en attendant le Messie ou le Mahdi dont la venue annonce la fin des temps? Si la plupart des chefs religieux ont affirmé qu'il fallait attendre humblement et patiemment, d'autres, au contraire, veulent préparer le chemin du Rédempteur, hâter sa venue. Le fondamentalisme révolutionnaire adopte cette conception de la religion que l'on trouve dans le millénarisme chrétien qui vise à hâter le millénium, l'âge d'or de mille ans censé régner après la Parousie, ou dans le mouvement du Mahdi au Soudan au XIX ${ }^{\mathrm{e}}$ siècle. Le fondamentalisme révolutionnaire est donc " un système où la religion investit l'ensemble du champ politique, en réduisant la complexité de la vie à un principe explicatif unique, violemment exclusif de tous les autres" (p. 50).

D'après É. Barnavi, les religions révélées connaissent plus que d'autres la tentation du fondamentalisme révolutionnaire. À la différence du bouddhisme qui aide à échapper à la condition humaine, les monothéismes considèrent que la religion détient une vérité transcendante et absolue, exclusive de toute autre, et le christianisme est celle qui a poussé le plus loin cette affirmation théologique. S'étant développé dans une tradition philosophique, le néoplatonisme, qui considère la vérité en soi comme l'expression d'une réalité ontologique, il estime que la vérité est, et que les hommes doivent la découvrir.

\section{La laïcité : une source d'incompréhension}

Le fondamentalisme révolutionnaire, qui place la loi de Dieu au-dessus de celle des hommes, ne prépare pas à accepter la sécularisation que défend la laïcité. É. Barnavi souligne que cette dernière est née en Occident d'une histoire particulière qui lui a légué une conception du sacré qui n'a pas de sens ailleurs. Pour exprimer ce concept qui n'existe pas dans leur langue, le turc a adopté le terme français, laik, et les langues sémitiques ont dû créer des néologismes : l'arabe ilmani signifie " rationaliste ", "érudit ", et l'hébreu khiloni " profane " (p. 35).

À la différence du monde musulman, écrit É. Barnavi, l'Occident chrétien connaît la laïcité, car l'État moderne s'est émancipé de l’Église : Il est né quand le souverain a exercé un pouvoir qui n'était pas d'Église. En Europe, le divorce entre l'État et les Églises a été possible grâce à cette particularité du christianisme qu'est l'existence de deux pouvoirs, l'un temporel, l'autre 
spirituel. En faisant de Rome sa capitale, l'Église a été modelée par l'État, et elle avouait ainsi qu'il y avait une compétition entre le pape et l'empereur. Dans ce face-à-face, l'Église a imposé à l'État des bornes morales, l'État a étouffé la tentation théocratique de l'Église (p. 68-69, 75, 77).

La laïcité française, qui fait de la religion une affaire privée, est cependant une source d'incompréhension pour beaucoup de musulmans qui voient en elle une arme dirigée contre les religions, une idéologie athée. Aux États-Unis, en revanche, la révolution s'est fait la Bible à la main, si bien que la séparation de l'État et des Églises ne signifie pas séparation de l'État et de la religion (p. 70-71).

\section{Retour sur le passé eschatologique de l'Europe}

Afin de montrer que les violences perpétrées par des musulmans ne sont pas consubstantielles à l'islam, D. Crouzet et J.-M. Le Gall font des comparaisons entre la crise que traverse aujourd'hui l'islam sunnite et les déchirements qu'ont connus - et subis - les chrétiens de l'Europe occidentale aux XVI ${ }^{\mathrm{e}}$ et XVII ${ }^{\mathrm{e}}$ siècles. Ils rappellent que les guerres de Religion ont éclaté en Europe parce que le pouvoir était fragile et, surtout, parce que la fidélité et la passion religieuses l'emportaient sur toute autre appartenance. Celui qui ne partageait pas votre foi n'était plus un voisin mais un ennemi de Dieu, un hérétique qu'il fallait combattre dans le cadre d'une guerre sainte et d'une croisade de l'intérieur. Les Européens se sont donc combattus entre catholiques et protestants, mais également au sein de leurs communautés : chez les catholiques français, les " ligueurs " ont combattu les " politiques ", chez les protestants anglais du XVII ${ }^{\mathrm{e}}$ siècle, une guerre opposa les puritains aux membres de l'Église épiscopalienne (p. 20).

Ce rappel des guerres de Religion dans l'Europe des $\mathrm{XVI}^{\mathrm{e}}$ et XVII ${ }^{\mathrm{e}}$ siècles permet aux auteurs d'établir des analogies avec les événements dont nous sommes les témoins : la coïncidence entre l'essor du djihadisme et des califes autoproclamés, et l'effondrement des États en Afghanistan, en Libye, en Syrie, en Irak et au Yémen font songer à la perte de légitimité de la monarchie française aux yeux de nombreux sujets d'Henri III; l'essor de l'actuel conflit au sein du monde musulman entre sunnites et chiites, entre intégristes et modérés, rappelle les guerres entre catholiques et protestants et les conflits au sein des communautés chrétiennes du XvI ${ }^{\mathrm{e}}$ siècle; on trouve chez les islamistes d'aujourd'hui une rhétorique des signes de la fin des temps comparable à celle des " guerriers de Dieu " du XVI ${ }^{\mathrm{e}}$ siècle (p. 21, 24).

D. Crouzet et J.-M. Le Gall développent des exemples tirés de l'histoire politico-religieuse de l'Allemagne en 1524-1525 et 1534-1535 afin de montrer que l'intolérance et la violence naissent dans un contexte particulier. En Allemagne, des croyants s'en prirent aux biens ou à la personne de leurs voisins parce qu'ils vivaient dans une société marquée par des difficultés économiques et saturée de discours eschatologiques : ils croyaient que la fin des temps était proche et s'y préparaient. 
Pendant la guerre des Paysans (1524-1525), des protestants commirent des actes iconoclastes : des crucifix furent jetés dans les rivières pour symboliser la mort du Diable, une image de saint François fut pendue en Saxe. Celui qui commettait de tels forfaits pensait accomplir un acte de justice sacrée : il restaurait la gloire divine offensée par les impies. De même que des islamistes tiennent aujourd'hui des discours apocalyptiques, des croyants interprétaient des signes divins et prédisaient la fin des temps : vers 1520, on se souvint que dans les années 1480 Johannes Lichtenberger avait prédit un déluge qui détruirait presque toutes la Terre en 1524, et que l'astrologue Johann Stoeffler (1452-1531) avait annoncé des catastrophes pour cette même année. Dans un tel climat d'inquiétude, 51 livres publiés en 1523-1524 évoquent un cataclysme imminent, que certains crurent voir dans le dur conflit qui ravagea le sud de l'Allemagne à partir de 1524 (p. 25-26).

Les anabaptistes prirent le pouvoir à Münster en février 1534 et ils édictèrent aussitôt des mesures pour faire triompher ce qu'ils croyaient être la volonté de Dieu. Ils s'attaquèrent aux images des églises, détruisirent tous les livres qu'ils trouvaient, à l'exception de la Bible, interdirent de posséder des biens ou de l'argent, qui furent mis en commun, et imposèrent une législation biblique qui prévoyait la peine de mort pour le meurtre, le vol, l'avarice, le mensonge et l'insubordination de la femme contre le mari. Ils instituèrent la polygamie afin de peupler Münster qui, d'après eux, serait épargnée par le cataclysme final. Pour mettre fin à cette monarchie eschatologique qui renversait l'ordre moral, social et politique, les princes protestants prirent les armes et s'emparèrent de Münster pendant la nuit du 24 juin 1535.

Cet épisode inspire deux réflexions à D. Crouzet et à J.-M. Le Gall. D'une part, les religions monothéistes partagent un imaginaire eschatologique qui exige le combat contre l'adversaire, la mise en place d'une terreur censée transformer les individus en des guerriers de Dieu qui, grâce à leurs actions, peuvent accéder au statut de justes, de purs, de saints. D'autre part, les hommes qui croient en l'imminence de la fin des temps sont angoissés à l'idée qu'ils n'ont plus beaucoup de temps pour préparer leur salut, mais ils pensent que leur sacrifice les sauvera aux yeux de Dieu. La violence est alors conçue comme " un outil de purification de soi et du monde " (p. 32).

Pour les trois historiens, le fondamentalisme et la pensée eschatologique préparent des esprits à tuer. À certains moments de leur histoire, écrivent-ils, les religions, et particulièrement les monothéismes, encourageraient certains de leurs fidèles à recourir à la violence contre leurs adversaires potentiels pour réaliser ce qu'ils croient être le dessein divin.

\section{Violence et religion}

Les trois auteurs consacrent des développements précis aux assassinats commis au nom de Dieu. D. Crouzet et J.-M. Le Gall montrent comment les " guerriers de Dieu " justifiaient et pratiquaient cette violence, tandis qu'É. Barnavi analyse la violence islamiste au XXI ${ }^{\mathrm{e}}$ siècle. 


\section{Le paradigme violent de l'âge moderne, d'après D. Crouzet et J.-M. Le Gall}

$\mathrm{Au}$ milieu du $\mathrm{XVI}^{\mathrm{e}}$ siècle, des catholiques étaient persuadés que la violence éradiquait le "mal " sur terre et purifiait de ses péchés celui qui la perpétrait en le faisant participer à la justice divine. À partir de 1560, certains se firent le bras vengeur de Dieu et n'hésitèrent pas à massacrer ceux qu'ils jugeaient impurs. Ils tuaient pour venger la majesté de Dieu en s'acharnant sur leurs cadavres qu'ils éventraient, mutilaient et rendaient informes. Cet acharnement avait pour eux un sens : comme leurs victimes s'étaient séparées du Dieu de l'Église romaine en se convertissant au protestantisme, elles avaient cessé d'être des créatures faites par Dieu à son image; elles étaient sorties de l'humanité (p. 33)

Tuer l'ennemi de Dieu n'était pas un péché, mais adhérer à la justice d'un Dieu qui ne tolère ni l'infidélité, ni le blasphème. Les tueurs coupaient donc la langue de leurs victimes et considéraient que les atrocités qu'ils commettaient étaient sacrées parce qu'elles leur apportaient, ainsi qu'à la chrétienté, le salut. La loi de Dieu passait pour eux avant la loi du roi, et Henri III, qui s'opposa à cette conception du pouvoir, devint une figure de l'Antéchrist et fut assassiné. Comme pour les islamistes d'aujourd'hui, la mort importait peu aux "guerriers de Dieu " catholiques : ils se croyaient possédés par l'Esprit divin, et la mort les faisait entrer dans l'éternité (p. 34). Pour celui qui tue au nom de Dieu, la guerre et le meurtre sont justes, puisque l'assassinat de l'hérétique est justice de Dieu (p. 35).

Le Dieu des " guerriers de Dieu " n'est pas un Dieu miséricordieux ou compassionnel, mais un Dieu de colère et de jalousie. Pour les " fous de Dieu " de l'Europe moderne, seuls la guerre et le massacre pouvaient l'amener à pardonner aux hommes et à oublier leur infidélité et leur offense. Chaque chrétien devait donc devenir son bras armé, et la guerre devenait sainte pour combattre l'ennemi de Dieu, perçu comme une malédiction. Dans sa Response à quelque apologie que les hérétiques ces jours passés ont mis en avant ${ }^{11}$..., le docteur en théologie Antoine de Mouchy (1494-1574) expliquait que Dieu avait commandé la mort dans une infinité de citations, surtout vétérotestamentaires. Il multipliait donc les affirmations péremptoires : les huguenots méritaient le feu comme la fille du sacrificateur qui se prostituait (Lévitique 21,9), Dieu avait dit que le blasphémateur devait mourir par lapidation (Lévitique 24,14), et l'idolâtre par le glaive (Exode 22,19).

Les fidèles vivaient souvent dans un état d'exaltation favorable à tous les dérapages. Pendant l'hiver 1589, le témoignage de Pierre de L'Estoile décrit la haine des Parisiens contre Henri III qui a fait assassiner le duc et le cardinal de Guise : les processions pénitentes, les cérémonies d'affliction pour les Guise tués, la croisade intérieure nourrissaient et entretenaient un désir de vengeance; le désir de tuer devenait don de soi au Christ. Il fallait punir le roi responsable de la colère de Dieu. Le dominicain Clément fut

11. Paris, chez Claude Frémy, 1558. 
donc exalté par les ligueurs comme un "saint ». Violence et sainteté étaient désormais synonymes.

Les commentaires de D. Crouzet et de J.-M. Le Gall sur les meurtres accomplis par les catholiques $\mathrm{au} \mathrm{XVI}^{\mathrm{e}}$ siècle aident à comprendre la violence des islamistes. Pour les prédicateurs et les polémistes de l'Église romaine, celui qui mourait pour la foi obtenait la vie éternelle. Cette violence, innocente et pure car voulue par Dieu (p. 39), était un devoir pour le croyant. L'hérétique devait être pourchassé comme une bête et offert à la vengeance de Dieu. Il devait mourir pour le plaisir de Dieu et le salut des chrétiens. Le guerrier de Dieu ne devait pas hésiter, d'après certains prédicateurs, à tuer un frère ou un fils (p. 40).

\section{La violence islamiste}

Aujourd'hui, d'après É. Barnavi, l'islamisme serait la forme la plus nocive du fondamentalisme révolutionnaire. Il insiste sur le fait que sa violence ne s'explique pas par le Coran (on y trouve ce qu'on y cherche) mais par l'histoire. L'islam, écrit-il, a toujours confondu spirituel et temporel. Mahomet fut à la fois prophète et chef de guerre, fondateur de religion et législateur, dirigeant d'une communauté de croyants qui fut en même temps le premier État musulman. Très vite, le pouvoir politique et militaire des califes est passé à des dynasties incapables de prétendre à la légitimité religieuse. Or en islam, seul le pouvoir religieux est pleinement légitime. Si en Occident, le roi donne la loi, en terre d'islam, il est censé exécuter une Loi qui le précède et le dépasse puisqu'une loi légitime n'est qu'une variation sur les préceptes du Coran et de la sunna (p. 99-101).

Aujourd'hui, l'islamisme est l'islam intégriste, d'inspiration wahhabite. Son objectif est d'islamiser la société en fondant un État authentiquement musulman. L'État n'a pas d'importance : c'est un outil dont il faut se servir pour atteindre un objectif qui le dépasse. Autrement dit : les intégristes et les fondamentalistes veulent appliquer la charia et ramener les individus vers l'islam, tandis que les fondamentalistes révolutionnaires cherchent à instaurer un ordre islamique mondial (p. 112-113).

É. Barnavi analyse la stratégie des islamistes révolutionnaires. Dans À l'ombre du Coran, l'Égyptien Sayyid Qotb (1906-1966) affirmait que la guerre entre les États-Unis (et leurs alliés juifs, " croisés ") et les musulmans était inévitable et s'achèverait par la mise en place du royaume de Dieu sur terre, c'est-à-dire l'ordre islamique mondial. Qotb et les islamistes révolutionnaires sont favorables au " choc des civilisations" (p. 114-115). Depuis une quarantaine d'années, à défaut de pouvoir acquérir une impossible légitimité, le pouvoir musulman compose avec les "fanatiques " en passant avec eux une sorte de contrat tacite : à lui l'État, à eux la société. À partir des années 1970, la charia est devenue source principale du droit ou seul code légal dans de nombreux pays musulmans, les procès pour homosexua- 
lité, apostasie et blasphème se multiplient, et les minorités (coptes, chrétiens de Terre sainte, etc.) sont persécutées (p. 118-119).

Forts de leur connaissance des violences chrétiennes des $\mathrm{XVI}^{\mathrm{e}}$ et $\mathrm{XVII}^{\mathrm{e}}$ siècles, D. Crouzet et J.-M. Le Gall expliquent que la violence des islamistes a un sens. Ils se demandent si elle est un réflexe de survie d'un islam qui se sent menacé par l'occidentalisation et la mondialisation, ce qui ferait d'elle une " raison " alternative à la raison " autonomisée " du temps de l'Encyclopédie (p. 3). En tout cas, les hommes qui commettent les attentats ne sont pas des " monstres " ou des "barbares", mais des hommes banals, médiocres, " normaux ", morts pour leurs idées. Leur mort n'obéit pas à une pulsion nihiliste : elle leur assure auprès de certains une sacralisation et témoigne d'un esprit sacrificiel. Ils sont morts " saintement " et leur violence est une "théophanie ». Ils ne redoutent pas la mort; ils la recherchent parce qu'ils sont convaincus que le devoir sacré consiste à mourir pour sa foi. Dans leur esprit, béni est celui qui ne vit et ne meurt que pour Dieu. Ils sont en outre dans une dynamique eschatologique et narcissique (p. 5-6), car ils s'appuient sur des hadiths affirmant que le croyant qui a versé son sang pour Allah sera pardonné et libéré du châtiment de la tombe, verra sa place au paradis au moment de sa mort et ne connaîtra pas la peur du Jugement dernier. Le meurtre fait de celui qui tue un juste aux yeux de Dieu (p. 7).

Contrairement à une idée reçue, la violence des islamistes n'est pas seulement l'expression d'une désespérance de déclassés; elle est aussi la traduction d'une espérance individuelle qui devient collective, car l'élimination des impurs, des juifs, des blasphémateurs et des profanateurs, pour reprendre leur vocabulaire, donnera le salut (p. 7). La haine permet de demeurer "pur " parmi les " mécréants ". Elle incite à se faire tuer pour Allah, en martyr. Celui qui périt ainsi entre dans l'amour de Dieu, comme le rappelle le Coran, III, 163/169 : "Et ne crois point que sont morts ceux qui ont été tués dans le chemin d'Allah. Au contraire! Ils sont vivants auprès de leur seigneur, pourvus de leur attribution."

La violence islamiste actuelle n'est pas originale. D. Crouzet et J.-M. Le Gall rappellent que les islamistes s'inscrivent dans un phénomène politico-religieux appelé mahdisme, qui diffuse une idéologie messianique et eschatologique caractérisée par la rigueur des mœurs et la violence contre toute forme de mécréance au nom d'un retour au texte du Coran. Pour les islamistes, le monde contemporain est saturé d'injustices (massacres de Bosniaques par des Serbes, massacres de Tchétchènes par des Russes, massacres commis en Syrie par Bachar el-Assad). Leur martyre a un sens : il dit aux croyants que l'histoire va vers sa fin qui sera la paix universelle, et il doit effrayer les " mécréants " pour qu'ils comprennent que l'âge de la destruction s'approche pour eux (p. 12-13). Le combat des assassins de janvier 2015 s'inscrit donc dans un djihad international sans frontière et déterritorialisé qui vise à réaliser la communauté des croyants, l'oumma. Avec l'irruption de la violence islamiste dans les sociétés du Moyen-Orient et de l'Occident, on assiste donc moins au retour du religieux qu'au réveil du théologico-politique que, depuis 
cinquante ans, déplorent D. Crouzet et J.-M. Le Gall, les sciences sociales ont largement ignoré en France où l'on ne comprend plus ce que peut être la force du religieux dans une société (p. 17-18).

Sa connaissance des Ligueurs convainc É. Barnavi qu'il faut croire sur parole les "soldats de Dieu ", prendre les islamistes au mot et s'attendre à ce qu'ils fassent ce qu'ils ont annoncé. Il en déduit même que le combat contre le fondamentalisme révolutionnaire musulman sera la grande affaire du XXI ${ }^{e}$ siècle. Il sera d'autant mieux combattu que les Européens sauront pourquoi il les frappe. D'après l'historien et diplomate, les Européens cherchent aux guerres de Religion des causes " raisonnables ", c'est-à-dire économiques, sociales, politiques, territoriales. Or, écrit-il, la raison profonde d'une guerre de religion est pourtant la religion, pas l'argent, le territoire ou le régime politique.

\section{Comment lutter contre le fondamentalisme révolutionnaire musulman?}

É. Barnavi, D. Crouzet et J.-M. Le Gall ont des avis divergents sur la manière de lutter contre le fondamentalisme révolutionnaire musulman. É. Barnavi, qui est citoyen d'Israël, un pays en état de guerre depuis sa création en 1948 et qui combat régulièrement le Hamas et le Hezbollah, deux formations qui recourent à la violence pour des raisons politiques et religieuses, se fait peu d'illusions sur la capacité des États européens à venir à bout de la violence islamiste. Ses jeunes collègues parisiens, en revanche, citoyens d'un État en paix et partisans convaincus des bienfaits de la laïcité à la française et de l'universalité du discours humaniste, se montrent plus optimistes que leur aîné et voient dans l'éducation une arme essentielle pour faire triompher l'esprit des Lumières sur l'obscurantisme.

\section{Refuser le « dialogue des civilisations »?}

Dans la conclusion de son " pamphlet politique ", É. Barnavi s'inquiète de la capacité de l'Europe à gagner sur le plan moral son combat contre le fondamentalisme révolutionnaire musulman. D'après lui, la société libérale a perdu le sens du sacré (et non du religieux), et il se demande s'il est possible de ressusciter une religion civile fondée sur les Droits de l'homme, une constitution et la République (p. 166-167). Il insiste sur la nécessité de défendre à tout prix la laïcité et s'irrite de constater que les sociétés qui respectent la laïcité, autrement dit la liberté, ont inventé pour discuter avec ceux qui ne comprennent même pas ce que veut dire ce mot le "dialogue des civilisations ", qu'il qualifie de " miroir aux alouettes" (p. 167).

Il juge inutile de parler des textes sacrés avec des fondamentalistes pour plusieurs raisons : ces textes ne disent que ce qu'on veut leur faire dire, il n'existe pas d'interlocuteurs qualifiés des religions, et la ligne de fracture passe au cœur des religions. É. Barnavi estime avoir plus d'affinités avec 
un musulman éclairé qu'avec un juif fondamentaliste qui ose comparer l'évacuation de la bande de Gaza avec le camp d'extermination d'Auschwitz (p. 168). Convaincu que le dialogue entre la civilisation et la barbarie est impossible, il formule à l'attention de son lecteur européen ce sombre avis : " Il vous faudra réapprendre à faire la guerre. Il vous faudra vous armer de patience et de convictions, et tracer bravement la ligne de défense en deçà de laquelle vous ne pourrez ni ne voudrez reculer" (p. 168).

\section{Mise en garde contre quelques tentations, et clarifications}

D. Crouzet et J.-M. Le Gall ne partagent pas ce sombre avis et consacrent davantage de pages que leur collègue aux moyens d'enrayer la violence islamiste. Ils misent non pas sur l'action militaire, mais sur le développement de l'éducation et de l'enseignement. Leur refus de la guerre n'est ni une forme d'angélisme ni un appel à un compromis avec ceux qui tuent au nom de Dieu. Les deux auteurs considèrent comme des " dévoiements "laïcards" " les raisonnements qui font des signes culturels des symboles religieux de l'obscurantisme, mais ils plaident avec vigueur en faveur du rejet des accommodements raisonnables avec l'islam intégriste. La République ne doit ni ravaler les principes laïcs à des contingences historiques, ni relativiser l'impératif des principes universels des droits humains, qui ne sont pas valables pour la seule Europe (p. 73).

D. Crouzet et J.-M. Le Gall clarifient également le vocabulaire utilisé par les islamistes pour justifier leurs actes. Ils rappellent d'abord que les notions de profanation ou de blasphème n'ont de signification que pour le croyant; ce sont des notions relatives (p. 59). Or en février 2006, après la publication des caricatures danoises, l'OCI (Organisation de la conférence islamique) a réclamé que les Nations Unies adoptent une législation interdisant les atteintes aux religions (p. 60). Cette revendication est due au fait que l'interdit de l'image est l'ultime bastion de l'islam, bien que le Coran n'interdise pas la représentation du Prophète mais seulement celle de Dieu pour éviter l'anthropomorphisation. Depuis la naissance de l'islam, des musulmans ont donc réalisé des images du Prophète, même si l'école wahhabite s'appuie sur quelques hadiths pour prôner l'iconoclasme, au risque de prendre Mahomet pour Dieu (p. 61-62).

Les auteurs clarifient aussi le statut de " martyr". Dans la tradition chrétienne les martyrs acceptent la mort qui leur est donnée par leur persécuteur; ils ne recherchent pas le suicide. En revanche, les sha'hids ou martyrs islamistes d'aujourd'hui font de leur mort une offrande; ils s'offrent sacrificiellement pour que la Parole de Dieu soit élevée plus haut, en apportant la mort aux mécréants (p. 67).

Les auteurs rappellent que la violence islamiste cherche à caricaturer des symboles de l'Occident : à l'émancipation féminine répondent le voile des femmes, la polygamie et la réduction en esclavage; à la fin des discriminations sexuelles répond la mise à mort d'homosexuels; l'école, symbole 
d'émancipation, est fermée ou détruite. Face à un Occident qui sacralise l'art et le patrimoine, les islamistes détruisent des œuvres comme les statues de Bouddha de Bamyam (2001) ou les statues assyriennes du musée de Mossoul (2015) (p. 65).

\section{Une réflexion sur les sorties de guerre}

D. Crouzet et J.-M. Le Gall proposent une réflexion sur la façon dont les Européens sont sortis du cycle des guerres de Religion aux $\mathrm{XVI}^{\mathrm{e}}$ et $\mathrm{XVII}^{\mathrm{e}}$ siècles. Les princes, dont l'autorité avait été contestée par les " hérétiques " et par les défenseurs inconditionnels de l'Église romaine, firent prévaloir les intérêts de l'État sur ceux de n'importe quelle confession. Ils affirmèrent que leur autorité était au-dessus de celle des Églises. Par conséquent, ils invitaient leurs sujets à faire passer l'obéissance au souverain avant celle qu'ils devaient au pape. Aucune autorité religieuse ne pouvait donc se permettre de les juger. Ces mesures avaient des conséquences importantes car elles remettaient en cause la théocratie pontificale qui prétendait jusqu'alors détenir un pouvoir supérieur à celui des princes (p. 50).

Pour éviter la guerre civile, qui menaçait ou avait déjà commencé à déchirer certains États, des théologiens et des humanistes laïques du $\mathrm{XVI}^{\mathrm{e}}$ siècle tentèrent de désamorcer la fureur divine des guerriers de Dieu en faisant observer que tout pouvoir étant établi par Dieu, on devait respecter et appliquer les lois des hommes. Certains voulurent aller plus loin pour empêcher les passions religieuses de déchirer la société. Le chancelier Michel de L'Hospital se fit théoricien du primat de l'ordre de la loi civile et penseur de la coexistence et de la concorde entre les confessions dont il jugeait le maintien impératif pour la préservation du vivre en commun. Son discours était un vibrant plaidoyer en faveur de l'amitié et une condamnation sans appel de la violence qu'il regardait comme un péché parce que, précisait-il, elle procède souvent des prophéties de charlatans qui prétendent parler à la place de Dieu. Le gouvernement doit faire régner la justice, lutter contre les passions et, surtout, empêcher la guerre. Michel de L'Hospital contribua à la réflexion des hommes qui finirent par négocier et imposer la paix entre catholiques et protestants en 1598.

\section{Un nouvel enseignement de l'histoire}

Après avoir ainsi posé les bases de leur argumentation, D. Crouzet et J.-M. Le Gall proposent ce qu'ils nomment " un réveil-matin de l'Histoire " qui redonnerait à l'enseignement sa place centrale dans la formation des futurs citoyens. D'après eux, l'une des premières conditions pour contrer l'attraction que le fondamentalisme islamiste peut exercer sur les esprits consisterait à restaurer la figure et l'autorité du maître dans les écoles et les lycées, car il transmet une universalité de connaissances qui dépasse les idéologies, dont font partie les religions (p. 76). 
Ils invitent également à repenser l'enseignement de l'histoire. En tant que spécialistes de l'histoire culturelle, ils plaident en faveur de l'enseignement du fait religieux. Pour sortir les élèves du piège tendu par le communautarisme, l'école de la République doit historiciser le religieux en expliquant que les livres sacrés des croyants ne sont ni des textes révélés, ni la parole divine, mais des documents écrits par des hommes à partir de traditions orales, dans une société donnée, à un moment donné. Le fait religieux doit être étudié comme un fait culturel, donc anthropologique, et inclure à côté des monothéismes, le chamanisme, les polythéismes et l'incroyance (p. 76-77).

D. Crouzet et J.-M. Le Gall formulent un projet ambitieux où l'histoire, loin de se limiter à enseigner les causes et le déroulement des faits, doit nourrir une philosophie de l'histoire qui propose une éthique de la civilisation des mœurs et de la coexistence collective contre les illusions messianiques. La mission de cet enseignement est de "donner à chacun les outils pour se préserver de l'envoûtement d'un devoir de violence édicté comme sacré " (p. 80-81) afin de faire de chacun un citoyen du monde qui ne connaît pas la guerre, comme l'espéraient Érasme et Thomas More. Les élèves et les étudiants doivent entendre un discours historique qui les invite à la solidarité.

É. Barnavi, D. Crouzet et J.-M. Le Gall se livrent à un exercice aussi difficile que stimulant. En cherchant à éviter les pièges de l'anachronisme, ils s'appuient sur leur connaissance des violences commises par les Européens pendant les guerres de Religion pour aider le lecteur à comprendre l'intolérance des djihadistes : leur violence n'est pas un phénomène nouveau et ils ne sont pas des hommes ou des femmes extraordinaires, mais des individus banals, mus par une haine des " mécréants ", qui croient agir au nom de Dieu en vengeant les blasphèmes qui l'outrageraient.

Les trois historiens partagent à peu près le même diagnostic sur les causes de la violence islamiste (le messianisme, l'eschatologie et la volonté de soumettre la société à la loi d'un Dieu vengeur) et s'accordent sur la nécessité de défendre la laïcité. En revanche, ils divergent sur les mesures à prendre pour combattre la violence islamiste, reflétant ainsi les interrogations de la société. É. Barnavi, qui n'est pas un va-t-en-guerre, puisqu'il est membre du mouvement israélien " La paix maintenant ${ }^{12}$ ", reste pessimiste quant à l'aptitude des Européens à recourir à la force sur leur territoire. D. Crouzet et J.-M. Le Gall préfèrent envisager une bataille intellectuelle sur le long terme en mettant l'accent sur les vertus de l'enseignement. Ils ne sont pas naïfs et, conscients des dangers auxquels fait face la société française, ils rappellent que des événements brutaux peuvent se dérouler

12. Mouvement indépendant des partis politiques, fondé en 1978 par 300 officiers de réserve de l'armée israélienne. Il milite en faveur du principe "Deux peuples, deux États " et d'une réconciliation entre Israël, le futur État palestinien, dont il réclame la reconnaissance, et les pays arabes voisins d'Israël. 
rapidement : au XVI ${ }^{\mathrm{e}}$ siècle, la France sombra dans les guerres de Religion en 48 mois environ, et dans les années 1930 le basculement de l'Allemagne dans le nazisme fut également rapide (p. 90).

Les trois auteurs rappellent que si l'histoire, dont il est difficile de tirer d'improbables leçons, ne permet pas de prophétiser l'avenir, elle aide à relativiser les attentats perpétrés au nom de Dieu dans le monde depuis une quinzaine d'années en proposant des comparaisons avec l'Europe des $\mathrm{XVI}^{\mathrm{e}}$ et XVII ${ }^{\mathrm{e}}$ siècles. En outre, ils redonnent à l'étude du fait religieux toute la place qui lui revient dans l'effort pour comprendre les motivations des guerriers de Dieu et plus fondamentalement les aspirations, les croyances et les pratiques des hommes et des femmes qui croient en Dieu.

\section{RÉSUMÉ}

Cet article présente deux ouvrages concis que trois historiens modernistes, spécialistes de l'histoire culturelle du $\mathrm{XvI}^{\mathrm{e}}$ siècle et des guerres de Religion en France, ont rédigé à propos de l'intolérance et de la violence islamistes qu'ils analysent à la lumière de ce que nous apprend l'étude des conflits religieux que l'Europe a connus aux $\mathrm{XVI}^{\mathrm{e}}$ et $\mathrm{XVII}^{\mathrm{e}}$ siècles : Les religions meurtrières, d'Elie Barnavi, et Au péril des guerres de Religion. Réflexions de deux historiens sur notre temps, de Denis Crouzet et Jean-Marie Le Gall. Les auteurs expliquent comment l'intolérance religieuse des chrétiens du $\mathrm{XVI}^{\mathrm{e}}$ siècle et des islamistes du $\mathrm{XXI}^{\mathrm{e}}$ siècle prend sa source dans le fondamentalisme et l'eschatologie. Ils décrivent ensuite les caractéristiques de la violence commise au nom de la religion, puis ils envisagent les conditions d'un apaisement des passions religieuses dans l'Europe du $\mathrm{XxI}^{\mathrm{e}}$ siècle en insistant sur la lutte contre le fondamentalisme révolutionnaire musulman et sur l'importance d'un enseignement tourné vers une réflexion sur la tolérance.

\section{ABSTRACT}

This article deals with two concise books that three historians specialised in 16th-century cultural history and the French Wars of Religion wrote about Islamic intolerance and violence: Les religions meurtrières by Elie Barnavi, and Au péril des guerres de Religion. Réflexions de deux historiens sur notre temps by Denis Crouzet and Jean-Marie Le Gall. The scholars analyse these facts in light of what we have learnt from the study of religious conflicts in $16^{\text {th }}$ and $17^{\text {th }}$ century Europe. They explain how $16^{\text {th }}$ century Christians' and $21^{\text {st }}$ century Islamic fundamentalists' religious intolerance is rooted in fundamentalism and eschatology. Then they describe distinguishing features of the violence perpetrated in the name of religion before considering the conditions necessary to soothe religious passions in $21^{\text {st }}$ century Europe by laying stress on the struggle against Muslim revolutionary fundamentalism and on the importance of teaching dedicated to thinking about tolerance. 